\title{
Haematological monitoring in psychiatry
}

\author{
Z. Latif
}

Received: 8 July 2009/ Accepted: 25 July 2009/Published online: 27 August 2009

(C) Royal Academy of Medicine in Ireland 2009

Sir,

Clozapine can substantially improve the quality of life of patients with schizophrenia by reducing the presence and severity of symptoms, decreasing the duration of hospitalization, and permitting most such patients to live outside institutions, but it can cause one of the most severe forms of idiosyncratic toxicity, agranulocytosis. Clozapine monitoring has proved to be highly successful in early detection and has prevented many fatalities.

There is a need to consider the value of routine haematological monitoring for other medications associated with blood dyscrasia [1] like phenothiazines and carbamazepines. To the best of our knowledge, there have been reports of two patients with blood dyscrasia with olanzapine and risperidone who previously developed blood dyscrasia during clozapine treatment $[2,3]$. This means that patients who develop clozapine-induced blood dyscrasia should have haematological monitoring regularly during treatment with other antipsychotics, even if they have not had any haematological adverse effects with that drug in the past [3].

Conflict of interest statement None.

\section{References}

1. Atkin K, Kendall F, Gould D, Freeman H, Lieberman J, O'Sullivan D (1996) Neutropenia and agranulocytosis in patients receiving clozapine in the UK and Ireland. $\mathrm{Br} \mathrm{J}$ Psychiatry 169:483-488

2. Dernovsek Z, Tavcar R (1997) Risperidone induced leucopenia and neutropenia. Br J Psychiatry 171:393-394

3. Thangadurai P, Jyothi KS, Gopalakrishnan R, Kuruvilla A, Jacob KS (2006) Reversible neutropenia with olanzapine following clozapine induced neutropenia: letter to the editor. Am J Psychiatry 163:1298
Z. Latif $(\bowtie)$

St Brigid's Hospital, Ardee, Louth, Ireland

e-mail: drzahidlatif@gmail.com 